\title{
Article
}

\section{Cognitive Neuroscience Methods in Enhancing Health Literacy}

\author{
Mateusz Piwowarski ${ }^{1, *(\mathbb{D})}$, Katarzyna Gadomska-Lila ${ }^{2}$ and Kesra Nermend ${ }^{1}$ \\ 1 Department of Decision Support Methods and Cognitive Neuroscience, University of Szczecin, \\ 71-004 Szczecin, Poland; kesra.nermend@usz.edu.pl \\ 2 Department of Organization and Management, University of Szczecin, 71-004 Szczecin, Poland; \\ katarzyna.gadomska-lila@usz.edu.pl \\ * Correspondence: mateusz.piwowarski@usz.edu.pl
}

Citation: Piwowarski, M.;

Gadomska-Lila, K.; Nermend, K. Cognitive Neuroscience Methods in Enhancing Health Literacy. Int. J. Environ. Res. Public Health 2021, 18, 5331. https://doi.org/10.3390/ ijerph18105331

Academic Editor: Paul B. Tchounwou

Received: 12 April 2021

Accepted: 13 May 2021

Published: 17 May 2021

Publisher's Note: MDPI stays neutral with regard to jurisdictional claims in published maps and institutional affiliations.

Copyright: (c) 2021 by the authors. Licensee MDPI, Basel, Switzerland. This article is an open access article distributed under the terms and conditions of the Creative Commons Attribution (CC BY) license (https:// creativecommons.org/licenses/by/ $4.0 /)$

\begin{abstract}
The aim of the article is to identify the usefulness of cognitive neuroscience methods in assessing the effectiveness of social advertising and constructing messages referring to the generally understood health promotion, which is to contribute to the development of health awareness, and hence to health literacy. The presented research has also proven useful in the field of managing the processes that improve the communication between the organization and its environment. The researchers experimentally applied cognitive neuroscience methods, mainly EEG measurements, including a metric which is one of the most frequently used to measure the reception of advertising messages, i.e., frontal asymmetry. The purpose of the study was to test cognitive responses as expressed by neural indices (memorization, interest) to the reception of an advertisement for the construction of a hospice for adults. For comparative purposes, a questionnaire survey was also conducted. The research findings have confirmed that there are significant differences in remembering the advertisement in question by different groups of recipients (women/men). They also indicate a different level of interest in the advertisement, which may result from different preferences of the recipients concerning the nature of ads. The obtained results contribute to a better understanding of how to design advertising messages concerning health, so that they increase the awareness of the recipients' responsibility for their own health and induce specific behavior patterns aimed at supporting health-related initiatives, e.g., donating funds for building hospices or performing preventive tests. In this respect, the study findings help improve the organizations' communication with their environment, thus enhancing their performance. The study has also confirmed the potential and innovativeness of cognitive neuroscience methods as well as their considerable possibilities for application in this field.
\end{abstract}

Keywords: public health; health literacy; cognitive neuroscience; EEG; advertisement

\section{Introduction}

A comprehensive approach to health requires constant strengthening of public health awareness, to which health literacy refers. It is also essential for health promotion, especially with regard to preventive health issues, as well as to people's involvement in various initiatives, such as supporting health promotion campaigns. In a narrow sense, health literacy is the ability of individuals to seek, process, and understand information necessary to make appropriate health decisions [1], the ability to make health-related decisions in the context of everyday life, including at home, in the community, in the workplace, and in the health care system [2]. The term also refers to a specific skill that is needed to successfully manage a large number of health-relevant tasks and decisions to be made each day $[3,4]$. Health literacy encompasses those cognitive mechanisms and social skills that affect the motivation and ability of individuals to successfully obtain, process, and use information in order to maintain or improve their health [5], such as reading, writing, counting, and retrieving information [6], using multimedia technologies, or problem solving $[7,8]$. However, health literacy depends on many factors. The determinants of 
individual health awareness are demographic and socio-cultural factors such as occupation, income level, social status, culture or language, as well as more personal factors, such as individual experience of illness and contacts with the health care system, or individual traits such as age, gender, race, education level, etc. [9]. These factors should be taken into account when selecting instruments for enhancing health awareness and health promotion as they influence the effectiveness of the steps taken.

A broader view of health literacy is related to empowerment. It emphasizes social skills, mainly in the area of communication or negotiation, that are necessary in the process of making health promoting decisions in practice [10]. From a public health perspective, the above is crucial in terms of improving health of whole communities, not just individuals [11]. This means that an inalienable part of health literacy is education [12]. Health literacy is also a useful tool in identifying health information delivery issues and empowering people to use this information to make proper health decisions [13]. From a public health perspective, what seems to be of particular importance is civic literacy [14], which relates to involvement in public life with its decision-making processes. The term refers to the skills that help a person (citizen) to be aware of public affairs and to be involved in decision-making processes. The key skills in this respect are: conscious and critical perception of media and their rational use as a tool for work, communication and learning (media literacy), as well as knowledge about social and governmental processes or the awareness that personal health-related decisions can affect the health of the whole community [14]. The idea underlying this change is that both public and private organizations should be considerably involved in efforts to improve health care systems and the health of individual citizens. In this view, health literacy points to a health care organization that uses strategies that make it easier for patients to engage in the process, navigate through the health care system, understand health information, and last but not least manage their health $[15,16]$. This highlights the importance of specific attributes of a health literate organization. The key ones include promotion of health literacy and its effective communication, which is also seen as an important attribute of a health literate organization. Communication is one of the key factors influencing the success of an organization. The recognition of needs, the choice of messages sent and their effectiveness are important for both the efficient implementation of management processes in the organization and for its contacts with the environment $[17,18]$. This requires effective tools to deliver the right information and provide the support people need to use the information when making correct health decisions [19]. Consequently, a need arises to find effective methods and tools to create health promoting messages, e.g., advertisements. Organizations operating within the health protection and care system often use advertising messages to achieve specific objectives related to their business profile. This group of organization includes hospices. Being institutions operating within the health care system, hospices often turn to the advertising messages to raise funds for their operation. The addressees of their messages may be both a wide range of recipients as well as a narrow group with a particular profile, hence the question about the effectiveness of such a message.

The purpose of this paper is to identify the usefulness of the methods of cognitive neuroscience when testing the effectiveness of public service advertising and designing messages concerning generally understood health promotion, which is going to contribute to public health awareness, to which health literacy refers.

Most often the evaluation of the advertising message is based on the opinions of its potential viewers. The research methods commonly used to assess the quality of such advertisements include focus groups, individual in-depth interviews, or population surveys (e.g., online, telephone) [20-23]. However, despite the advantages, the above research techniques also have certain limitations. The respondents' answers may depend on the interaction context, e.g., on the way the questions are phrased, the answers given by other respondents or by the focus group leader. Therefore, in many situations the effect of the advertisement on viewers is difficult, or even impossible, to assess with verbal measures $[24,25]$. Sometimes people sense that they know about something, but they are not 
able to extract this knowledge from their memory and transfer it in a verbal form. This can be explained by the functioning of their subconsciousness where a variety of experiences from every moment of a person's life is stored. It is assumed that up to $95 \%$ of thoughts, emotions, learning processes, and memorizing occurs beyond our consciousness. Research has shown that the majority of events reach consciousness only after about $300 \mathrm{~ms}$ from the occurrence of the stimulus. This means that shorter interactions, although recorded by the brain, are not consciously perceived and thus cannot be subject to verbal judgments [26]. The processes occurring in the subconscious, despite not being consciously controlled by a person, have a significant effect on their functioning and on the decisions they make [27-29]. In order to better understand some psychological processes, it is therefore advisable to analyze the reactions of the human brain and body to external stimuli perceived [30,31]. The study of physiological (including neurophysiological) parameters of the human body which determine the response to the stimuli in question can significantly expand the range of information about the reception of a given message. It allows researchers to obtain information unavailable for declarative research. Scientific research shows that males and females differ in brain activation during cognitive tasks. Research concerns among other things, tasks of mental rotation, visual stimulation, emotional recognition, working memory and verbal processing [32-34]. This also applies to the perception of TV advertising [35-39]. Therefore, in this article we focus on the analysis of the perception of advertising based on sex. Due to sexual dimorphism of the human brain, this type of research should be designed accordingly. The gender-related differences do not arise in every situation but, if they do, they can provide valuable guidance in designing announcements and advertising messages. The potential that lies in the methods of cognitive neuroscience which encourage their use in the area of building health awareness. The application of specific techniques helps design the message in such a way that it will reach a specific group of addressees more effectively. This can help shape the health awareness of a given group of recipients in the most desirable way, thus increasing the effectiveness of the organization's activities. Therefore, it seems justified to consider the use of cognitive neuroscience methods in this field to be innovative.

\section{Cognitive Neuroscience Methods in the Study on Advertising Messages}

The dynamic development of medical, biological, chemical, computer, or psychological sciences has led to the emergence of a new area of scientific research, i.e., cognitive neuroscience which integrates many scientific issues, such as psychology of cognitive processes, anatomy or human physiology (including human brain). It focuses on the neural basis of mental processes, combining theories of cognitive psychology and computer modeling with experimental data on the brain $[40,41]$. Methods of cognitive neuroscience supported by other techniques for measuring human physiological processes more and more often are finding applications in the studies on the multimedia content, such as video advertisements. EEG (electroencephalography) measurements, fMRI (functional magnetic resonance imaging), as well as GSR (galvanic skin response), HR (heart rate), EMG (electromyography) and eye tracking are used for this purpose [35,36,42-60]. Measurement techniques based on neuroscience are less prone to assessment errors and are more objective. They allow information to be obtained at its source (in the brain) before it is presented in the form of an opinion or judgment (e.g., surveys or interviews) [61-64]. Some of them, EEG for instance, are characterized by a very high temporal resolution, which allows for time-accurate measurements of people's reactions to the presented stimuli $[43,48,65]$. Various EEG metrics based on brain activity in its different parts and at different frequency ranges are used to assess the reception of media messages (advertisements). They are utilized, among others, to study the reception and processing of video stimuli. Numerous studies have confirmed that the effectiveness of advertising depends on cognitive processes of attention, memory and emotions [36,44,47,55,65-69].

Frontal asymmetry is one of the EEG metrics that are best described in the literature and most frequently applied in assessing the receipt of advertising messages. It is recorded 
at rest and under task conditions (when responding to a stimulus). The frequency range closely associated with frontal asymmetry is primarily the alpha band (8-13 Hz), but theta (4-8 Hz), beta (13-30 Hz), and even gamma (above $30 \mathrm{~Hz}$ ) bands are also used [70-72]. Frontal asymmetry is an indicator of asymmetrical brain activity in the frontal cortex between the left and right hemispheres. It is associated with emotional states and motivational systems that translate into human behavior. According to Davidson's model, left frontal brain activity indicates a tendency to approach a stimulus, to become interested in the stimulus. Relatively greater right frontal brain activity is associated with negative occurrences, withdrawal, and stimulus avoidance [52,73-75]. Stronger lateralization of frontal alpha (left-right) has been observed in a number of studies on advertising messages, in response to the positively valenced content of video scenes and advertising clips [21,36,53,76]. It has been linked to dopaminergic reward system activation [76,77]. Frontal asymmetry alpha is considered as a biomarker of the behavioral activation system [67,78]. Based on this knowledge, an Approach Withdrawal index can be defined to reflect approach or withdrawal behavior in relation to the presented stimulus.

The measurements of the electrical activity of the frontocentral parts of the brain permit study of the processes of encoding and memory retrieval. An increase in the power of the EEG signal in this area within the theta range $(4-8 \mathrm{~Hz})$ and at higher gamma frequencies is associated with the encoding process [79-81]. According to the HERA hemispheric encoding/retrieval asymmetry model, the left part of the prefrontal cortex is more involved in the encoding process of episodic memory. In contrast, the right prefrontal cortex is responsible for retrieving this memory [82-84]. The assumptions for this model are consistent with the results of many other studies which have confirmed an increase in theta and gamma power in the frontal parts of the brain. This applies to both memory encoding processes and to the memorization of different types of stimuli [80,85-88]. These properties have been utilized in a variety of studies on remembering television messages, advertising clips, and the impact of video stimuli [21,54,89-93].

The analysis of the world literature on the applicability of EEG signal measurements in the reception of advertising messages, as well as our own previous studies [56-58,60,94-98] confirm the correctness of the adopted research direction. Reaching and analyzing the brain response to the specific stimuli (in this case, scenes shown in public service advertisements) may bring measurable benefits to the entire health care system. Designing effective messages enhancing health literacy and those emphasizing the need to help people in difficult health situations may significantly support (financially, organizationally or image-wise) the functioning of organization dealing with broadly understood human health. Hence, the idea appeared of a research project where measurements of neurophysiological parameters are utilized and the thesis about the effectiveness of this type of research is verified.

\section{Materials and Methods}

\subsection{Participants}

The cohort consisted of thirty-one subjects (16 females and 15 males) with an age range between 22 and 68 years. The mean age and standard deviation for all participants were: 42.09 (SD = 3.83); for women: 40.75 ( $\mathrm{SD}=11.59)$; for men: 43.53 (SD = 6.39). The study subjects were university students as well as employees working in a variety of occupations. There was only one left-handed person in the research group, which is about 3\% of the total (this aspect was not considered in EEG analysis). They were healthy individuals who voluntarily submitted to the research procedure. The experiment was conducted in compliance with the Declaration of Helsinki (as updated in 2013) [99] and was approved by the Bioethics Committees at Regional Chamber of Physicians in Szczecin. Prior to the start of the research project, participants were informed about the study protocol (without providing details), as well as about the measuring devices used. All the participants gave their written consent to be included in the study and to their personal data processing. 


\subsection{Protocol and Stimuli}

The study was intended to reflect a real-life television viewing situation. The film shown was separated by two blocks of commercials. The film was a documentary about the natural environment and the advertisements were of different nature, both commercials and public service announcements. There were 6 video ads in the first advertising break and 7 in the second break, and they were randomly placed. The duration of the ads varied from 15 to 30 to $60 \mathrm{~s}$. The advertisement in question was released in the second block and lasted for $60 \mathrm{~s}$. The commercial was titled "Loved ones pass away happy" (vimeo.com/309422044 accessed on 21 September 2020) and was meant to encourage people to financially support the construction of a hospice (Figure 1).

\begin{tabular}{|c|c|c|c|c|c|c|c|c|c|c|c|c|c|}
\hline Baseline & $\begin{array}{l}\text { Film } \\
\text { (part I) }\end{array}$ & \multicolumn{4}{|c|}{$\begin{array}{l}\text { Advertising } \\
\text { block (no. 1) }\end{array}$} & $\begin{array}{l}\text { Film } \\
\text { (part II) }\end{array}$ & \multicolumn{6}{|c|}{$\begin{array}{c}\text { Advertising } \\
\text { block (no. 2) }\end{array}$} & $\begin{array}{c}\text { Film } \\
\text { (part III) }\end{array}$ \\
\hline PICTURE & VIDEO & $\vec{Q}$ & $\tilde{q}$ & 这 & $\hat{\alpha}$ & VIDEO & $\vec{Q}$ & $\tilde{q} \tilde{q}$ & 京 & $\hat{q}$ & Q & $\hat{\mathrm{q}}$ & VIDEO \\
\hline
\end{tabular}

Figure 1. Study protocol structure. The ad under study was placed in the second advertising break.

The storyline of the public service advertisement takes us emotionally from a state of sadness (an old man lying on a hospital bed) to the realm of dreams (a rocket trip into space). In the ad there are scenes showing: the figure (face) of an elderly man and a child, their walk together through a desert to the rocket, the interior of the rocket, their figures in spacesuits on seats, and finally an announcement is displayed encouraging people to support the construction of a hospice.

For the purposes of the study, seven specific scenes were extracted from the 60-s commercial. Each of them presents thematic fragments that are interesting in terms of their reception by the surveyed respondents. Scenes were extracted with an accuracy of $0.5 \mathrm{~s}$ (in brackets time intervals in seconds):

- (S1) An elderly (sad) man lying on a hospital bed $(0 \div 6.5)$;

- $\quad$ (S2) The smiling man wearing a spacesuit $(12.0 \div 13.0)$;

- (S3) A child reaching out to the man and then walking with him toward a rocket $(13.5 \div 25.0)$;

- (S4) The man with the child walking inside the rocket $(25.5 \div 31.0)$;

- (S5) The man fastening his seatbelt while seated with the child in the rocket seats $(31.5 \div 40.5)$;

- (S6) The smiling man wearing a buckled astronaut helmet $(41.0 \div 44.0)$;

- (S7) Announcement (text and voiceover appearing) about building a hospice and asking for financial support $(48.0 \div 60.0)$.

The entire advert was in a melancholic mood. The video was accompanied by soothing music. Voiceover appears only in scene S7.

The study was conducted in two stages. First, the participant's brain activity and, additionally, their electrodermal activity and heart rate were recorded. The initial phase of the measurement procedure involved the identification of a reference point (baseline), relative to which the neurophysiological responses of the subjects were determined. The stimulus used to determine the baseline was a photograph of a neutral nature (in line with IAPS [100]). The participants were asked to stare at the image presented on the monitor screen for a period of $1 \mathrm{~min}$. In the second part of the study, the participants completed a survey questionnaire in a separate room. The questionnaire was used to check whether the participants had not seen the advertisement before, whether they memorized anything, 
and to learn their opinion about the advertisement in question (according to different criteria). Following the subsequent steps of the research protocol, the respondents were asked questions by the interviewer. Initially, he asked which adverts they had memorized (in that short period of time). Then, he asked for a detailed description of the storyline of the advertisement. The details provided by the respondents were written down by the interviewer. Then, after the ads had been shown again, the respondents were asked to rate them.

\subsection{Apparatus and EEG Recordings}

The electrical activity of the subjects' brains was recorded using a g.Nautilus mobile device from g.tec. What was interesting for the study was the frontal lobe. A total of 8 measuring (wet) electrodes were placed in the locations: Fp1, Fp2, F3, F7, Fz, F4, F8 and $\mathrm{Cz}$, following the 10-20 standard. The ground (GND) was placed on the skin of the head, while the reference was placed on the left earlobe. Caps used in the study: g.GAMMAcap ${ }^{2}$, size: medium and large. Measurements were performed at an electrode-skin impedance below $10 \mathrm{k} \Omega$. The sampling frequency of the EEG signal was $500 \mathrm{~Hz}$, noise level: $<10.6 \mu \mathrm{V}$ RMS between 1 and $30 \mathrm{~Hz}$ (at highest input sensitivity).

The EEG signal was processed and analyzed using the Matlab package with EEGLAB toolboxes, FieldTrip and the authors' innovative software. EEG preprocessing included several steps [101]. In the first stage, frequencies of no interest due to the nature of the study were filtered out. The fifth-order Butterworth filter [2-30 Hz] was used to eliminate the slow-variable trend and high-frequency interference of, e.g., muscle origin. The electrodes were then placed and events were imported (identification of individual advertisements). Any bad channels they were removed (max. one channel) and then interpolated. Different approaches were used to eliminate artifacts from the EEG signal. Interference from electrodes was flagged and excluded from further analysis. Ocular artifacts were extracted using the ICA method (Infomax algorithm) [102]. Only one of the identified components was removed. After the signal was reconstructed, the process of eliminating epochs containing other artifacts was performed. For this purpose, the continuous signal was divided into one-second time windows and interference analysis was performed in such intervals. The following criteria for artifact determination were adopted: amplitude exceeding $\mathrm{V}$ and slope of the trend between windows exceeding V/s, with R-squared $=0.3$. Epochs marked as artifacts were removed from further analyses. A cleaned EEG signal was thus obtained and subjected to further processing and analysis.

\subsection{Indicators of Advertising Receipt Evaluation}

An Individual Alpha Frequency (IAF) was determined for each participant. The alpha and theta frequency bands analyzed in the study were determined based on the IAF. That was done according to the notation IAF $\pm x$, where $x$ is the integer used to define the beginning and end of the band in $\mathrm{Hz}$. The alpha band was defined as (IAF- $2 \mathrm{~Hz} \div \mathrm{IAF}+2 \mathrm{~Hz}$ ) and the theta band was defined as (IAF- $6 \div$ IAF-2) $[86,103]$. Global field power (GFP) was calculated for the obtained bands. GFP is a quantity that describing the total EEG activity at specific measurement points at a given time $[104,105]$. It corresponds to the standard deviation of the mean EEG amplitude from the electrodes at a given moment. Additionally, it is a parameter for analyzing EEG in the function of time. GFP was calculated from a specific set of electrodes according to the formula [53]:

$$
G F P=\frac{1}{N} \sum_{i=1}^{N} x_{\vartheta_{i}}(t)^{2}
$$

where: $\vartheta$ is the considered EEG band,

$N$ is the number of electrodes included in the area of interest,

$i$ is the electrodes index,

$x \quad$ is the EEG sample for time $t$ filtered for a given bandwidth $\vartheta$ and for a given channel $i$. 
From the GFP values, indices were calculated to determine memory processes (MI index) and the degree of interest in the presented stimuli (AW index).

To determine the MI index, data obtained from EEG measurements, from electrodes located above the frontal left part of the brain (Fp1, F3, F7), were used. The frequency band considered was theta. The MI index was calculated according to the following formula $[54,83,84]$ :

$$
M I=\frac{1}{N_{Q}} \sum_{i \in Q} x_{\theta_{i}(t)}^{2}=\text { AveragePower }_{\theta_{\text {left frontal }}}
$$

where: $x_{\theta_{i}}$ represents the $i$-th EEG channel in the theta band,

$Q \quad$ is the set of left channels (Fp1, F3, F7),

$N_{Q}$ represents its cardinality.

Higher MI values are interpreted as better memorization at a given point in time.

The AW index was determined on the basis of EEG data from measuring electrodes located in the frontal part of the brain, in both hemispheres (left side: Fp1, F3, F7, right side: Fp2, F4, F8). The frequency band included in the calculations covered the alpha waveband. The formula by which the AW index was calculated is as follows $[52,75,106]$ :

$$
A W=\frac{1}{N_{P}} \sum_{i \in P} x_{\alpha_{i}}^{2}(t)-\frac{1}{N_{Q}} \sum_{i \in Q} y_{\alpha_{i}}^{2}(t)=\text { AveragePower } \alpha_{\alpha_{\text {right frontal }}}-\text { AveragePower }_{\alpha_{\text {left frontal }}}
$$

where: $x_{\alpha_{i}}$ and $y_{\alpha_{i}}$ represent the $i$-th EEG channel in the alpha band,

$P$ and $Q$ are the sets of right channels and left channels,

$N_{P}$ and $N_{Q}$ represent their cardinality.

The approach/withdrawal (AW) index has been defined as the frontal alpha asymmetry. It is interpreted as a motivation to approach a stimulus or withdrawal. Higher values of it mean an increase in interest (approach) in the presented stimulus (advertising scenes), and lower values mean a decrease in interest (withdrawal) [73].

Eventually, the MI, AW index values were normalized (z-score) for each second of the advertisement using the mean and standard deviation of the index values calculated for the baseline. These calculations were performed as follows [35]:

$$
\text { Normalized index }(z-\text { score })=\frac{\text { index value }- \text { mean value }(\text { baseline })}{\text { standard deviation }(\text { baseline })}
$$

\subsection{Statistical Analysis}

A two-way analysis of variance (ANOVA) was used for the statistical analysis of the obtained EEG test results (MI, AW indices). The dependent variables were the values of MI and AW indices. Averaged values were used over three channels (left side: Fp1, F3, F7, right side: Fp2, F4, F8) for each participant. The first factor (independent variable) was the GENDER of the study participants considered at two levels: men (M) and women (W). The second factor was the SCENES of the advertisement analyzed at seven levels: scene 1 (S1), scene 2 (S2) and so on to scene 7 (S7). The assumptions of analysis of variance, namely tests for normal distribution of the dependent variable scores across groups, and homogeneity of variance were tested. Both main effects of factors (GENDER, SCENES) and the interaction effect (GENDER x SCENES) were analyzed. The number of repetitions of each combination GENDER $\times$ SCENES was 1 and the number of all experimental units was 14 . What was examined was the interaction of these two factors on the values of the calculated indices. Having established the fact of the overall F-test significance (the analysis of variance), post hoc comparisons were performed. They permitted assessment of between which groups statistically significant differences had occurred. The analyses were expected to provide answers to the following research questions:

1. Are there any differences in the mean values of MI, AW by gender? 
2. Are there any differences in the mean values of MI, AW for different advertising scenes?

3. Are there any interactions between the GENDER and SCENES factors?

4. Between which groups of the SCENES factor are there differences as regards the mean values for the GENDER factor groups?

The significance of the relationship between the answers of men and women to the survey questions was also tested. For this purpose, the chi-square test of concordance was used $\left(\chi^{2}\right)$.

\section{Research Results}

\subsection{Memorization Index}

When examining the effect of the GENDER factor, it was found that there were significant differences in the mean MI values between men and women: $\mathrm{F}(1,2127)=51.92$, $p<0.005, \eta_{P}^{2}=0.024$. Women obtained higher memorization values $(\mathrm{M}=0.34, \mathrm{SE}=0.03)$ than the male group $(\mathrm{M}=-0.04, \mathrm{SE}=0.04)$. No statistical significance was found as regards the effect of the SCENES factor: $\mathrm{F}(6,2127)=0.97, p=0.442, \eta_{P}^{2}=0.003$. Similarly, there was no statistical significance as far as the "Gender $\mathrm{x}$ Scenes" interaction effect was concerned: $\mathrm{F}(6,2127)=0.64, p=0.132, \eta_{P}^{2}=0.005$.

When comparing the distribution of mean MI values (95\% CI) recorded for men and women, a different distribution can be seen for each of the scenes under study (S1-S7) (Figure 2).

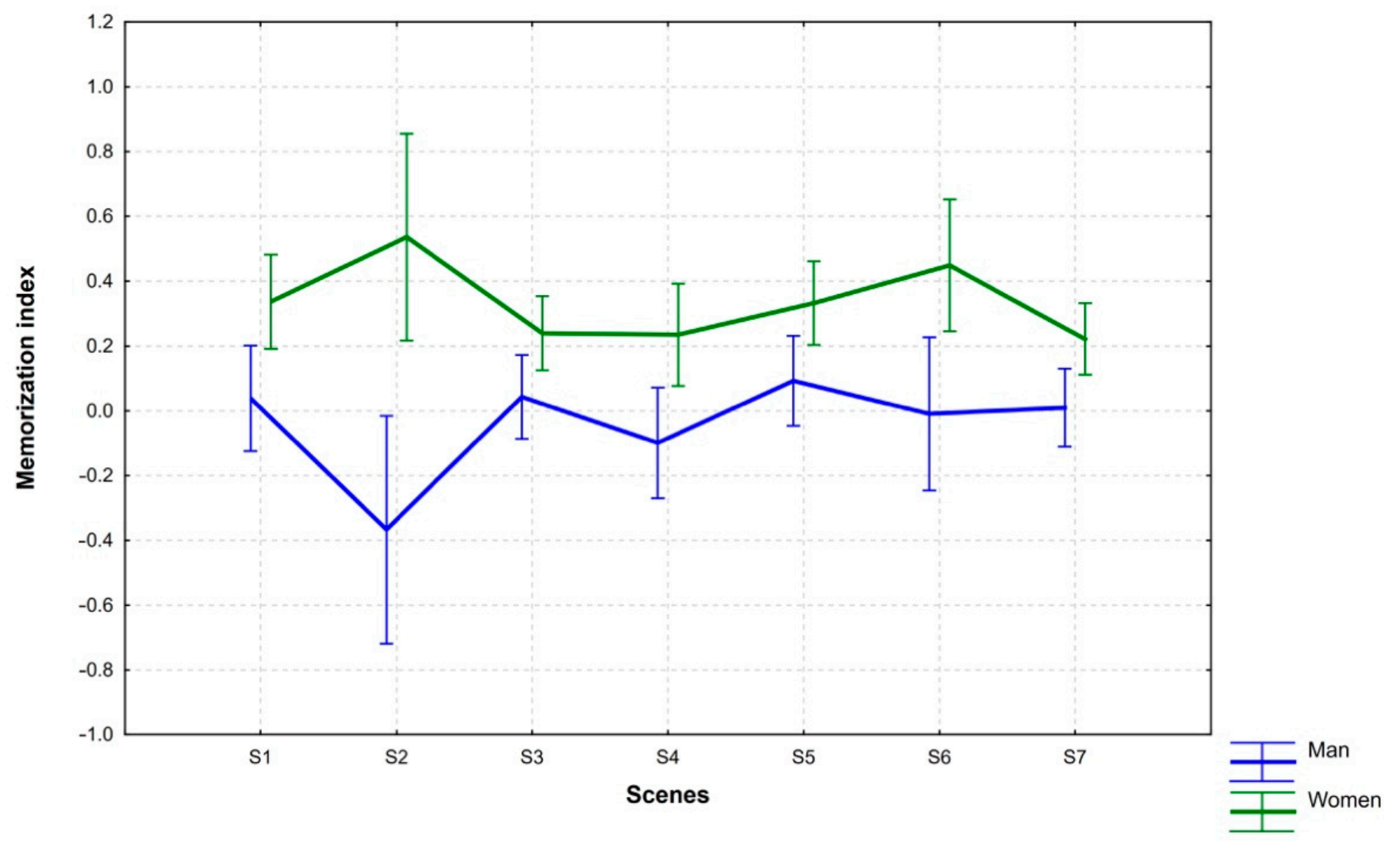

Figure 2. Differences in mean MI values between men and women as regards scenes under study.

Women obtained higher mean MI values for all scenes than the male group. Particularly in the case of $\mathrm{S} 2$, the mean MI values were high $(\mathrm{M}=0.536)$, while for S6 they were slightly lower $(\mathrm{M}=0.449)$. The lowest mean values in the group of women were recorded for S3 $(M=0.24), S 4(M=0.239)$ and $S 7(M=0.222)$. In the group of men, the mean MI 
values were the highest for S5 ( $M=0.093), S 3(M=0.043)$, and S1 $(M=0.039)$, respectively, and the lowest for S2 $(\mathrm{M}=-0.367)$.

In order to find out for which scenes the differences in mean values between men and women were the biggest, a pairwise comparison was made. That comparison was intended to provide the answer whether the content of the scenes (a sad man laying in bed, a smiling man, a child with a man, etc.) affected the differentiated levels of memorization by gender. The applied Tukey test (confirmed by the Bonferroni test) indicated a significant difference in MI values between the men and women as regards S2 $(p=0.014)$. In the case of other scenes these differences were irrelevant (S1: $p=0.295$, S3: $p=0.606$, S4: $p=0.214$, S5: $p=0.421$, S6: $p=0.184$, S7: $p=0.379$ ).

\subsection{Approach-Withdrawal Index}

The analyses of Approach-Withdrawal index values revealed no significant effect of the GENDER factor: $\mathrm{F}(1,2129)=0.14, p=0.70, \eta_{P}^{2}=0.00007$. A statistically insignificant result was also obtained regarding the SCENES factor: $\mathrm{F}(6,2129)=0.87, p=0.52, \eta_{P}^{2}=0.0024$. For the interaction effect of both "Gender $x$ Scenes" factors, significant differences were found between the mean AW index values for men and women: $\mathrm{F}(6,2127)=2.24, p=0.037$, $\eta_{P}^{2}=0.063$.

The distribution of mean AW values (95\% CI) for the male and female groups, for each scene (S1-S7) is shown in Figure 3.

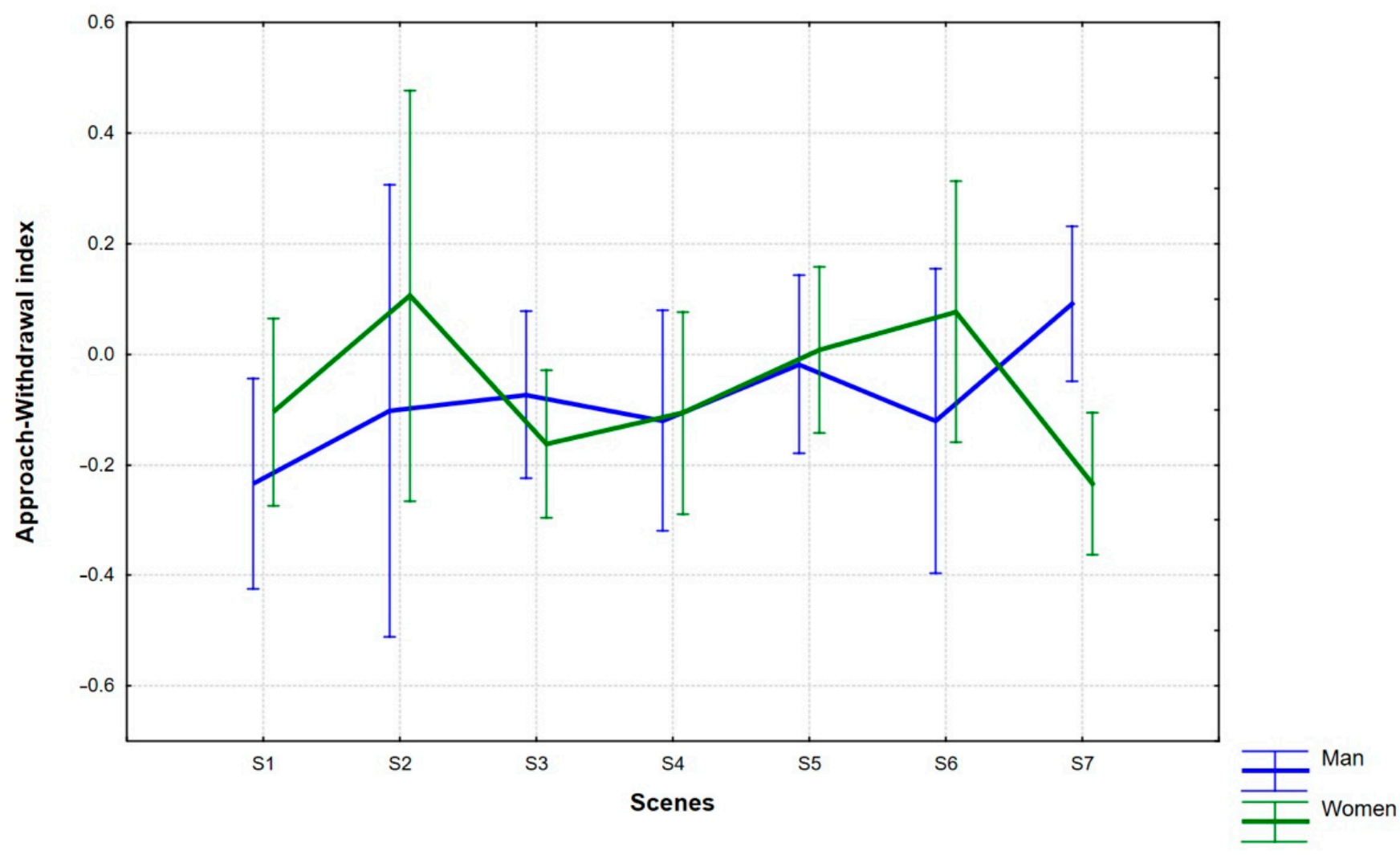

Figure 3. Differences in mean AW index values between men and women for scenes under study.

The highest mean AW values were obtained by women for S2 $(\mathrm{M}=0.11)$ and S6 $(\mathrm{M}=0.08)$, and the lowest for $\mathrm{S} 7(\mathrm{M}=-0.23)$. As regards male participants, the scene with the highest mean AW index value was $S 7(\mathrm{M}=0.09)$, while for $\mathrm{S} 1$ the index was the lowest $(\mathrm{M}=-0.23)$. Post hoc analysis (Fisher F-test) showed that the only statistically significant difference for this interaction effect was obtained when comparing the mean index values of GENDER factor regarding S7. Here, the male participants $(\mathrm{M}=0.09, \mathrm{SE}=0.07)$ achieved higher $\mathrm{AW}$ values than the female group $(\mathrm{M}=-0.23, \mathrm{SE}=0.07)$. For the other scenes, the 
comparisons of the mean index values proved to be statistically insignificant (S1: $p=0.0318$, S2: $p=0.459, \mathrm{~S} 3: p=0.386, \mathrm{~S} 4: p=0.918, \mathrm{~S} 5: p=0.812, \mathrm{~S} 6: p=0.286)$.

Scenes S2 (MI index) and S7 (AW index) appeared to be of key importance in terms of differences in the advertisement receipt between men and women. Scene S2 depicted a smiling elderly man dressed in a spacesuit. His smile activated stronger brain processes responsible for memorizing and interest in women than in men. In the group of women, that scene evoked the highest MI and AW index values. Another scene in which the man's smile appears is S6 (a man wearing a space helmet). Similarly to S2, the MI and AW index values for S6 amount to high values in women (in the group of men the indices are lower than for most other scenes).

The frames extracted from the advertisement video for S2 (at $0.5 \mathrm{~s}$ intervals) are shown in Figure 4a, while for S6 (at $1 \mathrm{~s}$ intervals) - in Figure 4b.

a)
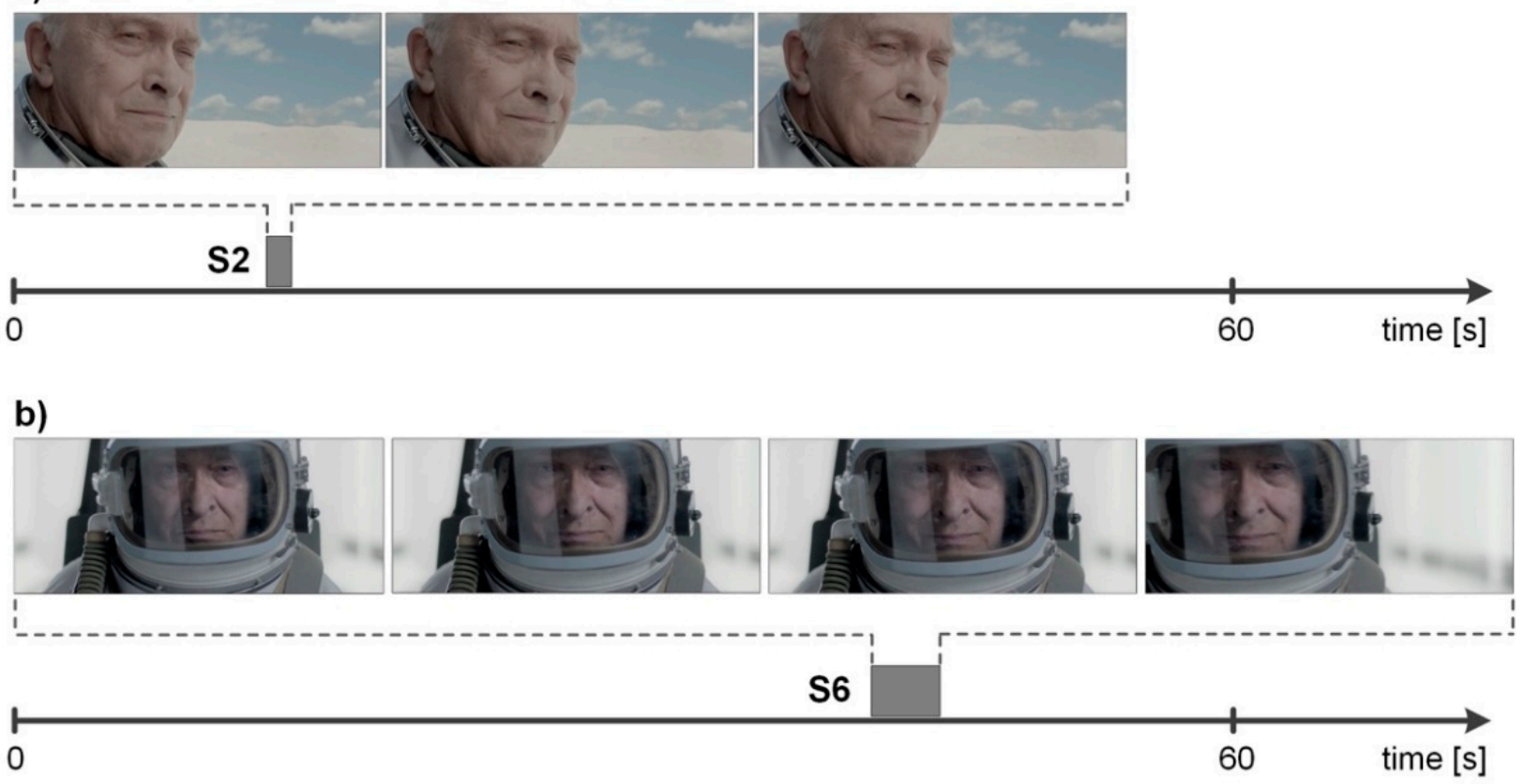

Figure 4. Frames extracted from advertisement under study: (a) for S2; (b) for S6.

As can be seen in Figure 4, the film shots in these parts of the advertisement are directly focused on the face, and the man's smile is very subtle. In S2, the change in his facial expression (smile) continues for a total of about $1.5 \mathrm{~s}$, and in S6 it lasts slightly longer, for about $4 \mathrm{~s}$. However, this was sufficient to elicit brain responses translating into varying receipt of the scenes by gender.

S7 divided into frames (at $2 \mathrm{~s}$ intervals) is shown in Figure 5.

This is the final advertisement part which continues for $12 \mathrm{~s}$ and contains information encouraging people to support the construction of an adult hospice. The scene is monochrome (black and white). The visual part is complemented by a voiceover that appeals for financial support via the provided website address.

Measurements of the electrical activity of the brain have shown that the high EEG temporal resolution makes it possible to examine even the elusive fragments of the message that last fractions of a second. Many of such stimuli remain beyond the conscience of the recipient. Therefore, it seems almost impossible to express any opinion about such fragments. 


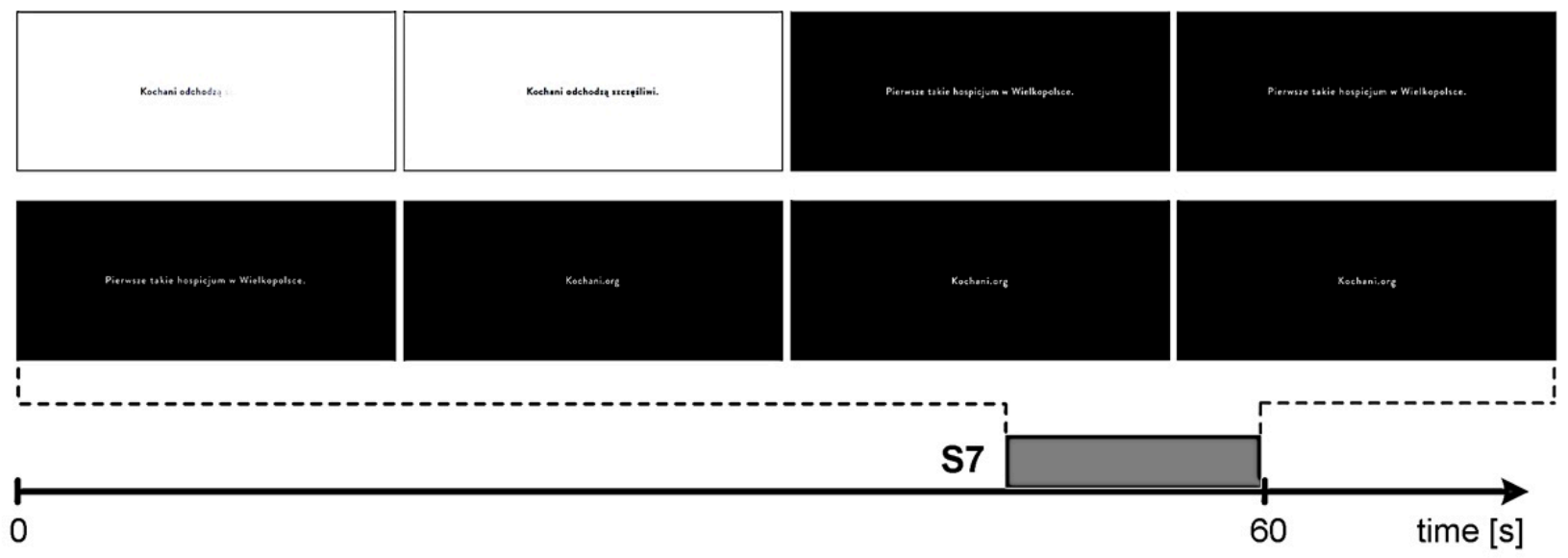

Figure 5. Frames extracted for S7 from advertisement under study.

\subsection{Survey Results}

One of the research objectives was also to compare the information gained from the neurophysiological measurements with the declarative information acquired from the questionnaire. Following the EEG measurements, respondents were asked if they remembered seeing the hospice advertisement shown during the study session (video interrupted by commercial breaks). More specifically, the question was worded as follows: Advertisements of which brands, products, services did you just see while watching the film? Various names were then mentioned by the interviewer, both of brands, products, services whose advertisements were shown and of those which were not (24 in total). When asked this question and the name of the hospice mentioned, a positive response was given by $74.19 \%$ of the respondents: 23 subjects, 14 men (about $61 \%$ ) and 9 women (about 39\%). The value of the chi-square statistic was shown to be statistically significant: $\chi^{2}(1, N=31)=5.560 ; p=0.018$. This means that there were relevant differences between women and men in terms of remembering the advertisement in question (with so formulated question).

When asking the respondents about the details remembered from the advertisement, i.e., what it was about, what was its main idea and what it advertised, in most cases the respondents had trouble describing the scenes they had seen. About $45 \%$ of the respondents (including $40 \%$ men and $60 \%$ women) were able to say something about this advertisement, most of them in very general terms. As regards scenes S2 and S6, only $6.45 \%$ of the respondents remembered a smiling and happy elderly man (including $50 \%$ men and 50\% women). In contrast, the message contained in scene S7 was remembered (at least partly) by $16.13 \%$ of respondents (including $40 \%$ men and $60 \%$ women).

The survey was continued after the advert was shown again. The respondents were asked if they generally liked the commercial, if the message was clear, if it inspired them to donate to support the hospice construction, and if they thought it might encourage other people to donate to that cause. The answers were given on a four-point scale: 0 -definitely NO, 1-rather NO, 2-rather YES, 3-definitely YES. They were also asked whether they would like to share any comments on the advertisement. Their answers were analyzed with a particular emphasis on the gender aspect. The results, along with an analysis of statistical significance, are shown in Table 1. 
Table 1. Results of statistical analysis of responses to survey questions given by men and women. Markings: YES (answers: rather YES, definitely YES), NO (answers: rather NO, definitely NO).

\begin{tabular}{|c|c|c|c|c|c|c|c|c|}
\hline \multirow{2}{*}{ Question } & \multicolumn{2}{|c|}{ Women (\%) } & \multicolumn{2}{|c|}{ Men (\%) } & \multirow{2}{*}{$\mathbf{N}$} & \multirow{2}{*}{ df } & \multirow{2}{*}{$x^{2}$} & \multirow{2}{*}{$p$} \\
\hline & YES & NO & YES & NO & & & & \\
\hline Do you like the advertisement? & 42 & 10 & 45 & 3 & 31 & 3 & 6.590 & 0.020 \\
\hline Is its message clear? & 39 & 13 & 39 & 10 & 31 & 3 & 0.803 & 0.376 (ni.) \\
\hline $\begin{array}{l}\text { Has it inspired you to donate to } \\
\text { support the hospice construction? }\end{array}$ & 32 & 19 & 39 & 10 & 31 & 3 & 2.889 & 0.268 (ni.) \\
\hline $\begin{array}{l}\text { Do you think that the advertisement } \\
\text { will inspire others to donate to support } \\
\text { the hospice construction? }\end{array}$ & 32 & 19 & 35 & 13 & 31 & 3 & 0.427 & 0.519 (ni.) \\
\hline
\end{tabular}

Of the four survey questions posed, a statistically significant difference between men's and women's responses was found only regarding the question of whether the advertisement was liked. The male respondents assessed it much more positively. The remaining answers concerning the advertisement evaluation did not differ between men and women. The remaining answers concerning the advertisement evaluation did not statistically differ between men and women, though the male respondents assessed it slightly more positively.

\section{Discussion}

The purpose of this study was to find out whether the brain activity (in its frontal part) evaluated by changes in the EEG signal power in the theta and alpha bands can be used to assess and explain the reception of advertising. According to current knowledge and proven research results, a change in theta power in left frontal region is associated with memory processing $[21,43,47,55,107]$. Increased cortical activity in this area during advert viewing is interpreted as a memory (encoding) process. This is consistent with the HERA model which assumes that the left prefrontal cortex (PFC) is more involved than the right PFC in encoding episodic memory. In turn, the right PFC is more involved than the left PFC in episodic memory retrieval [82-84]. By obtaining higher MI values in females for scenes S2 and S6 (based on the GFP power of the EEG signal in the theta band), we obtain confirmation of the increased level of encoding of these scenes in episodic memory. The influence of observed emotions (positive and negative) on the memory process is confirmed by numerous studies [108-111]. This fact can be explained by the higher MI values in women for scenes S2 and S6. In the context of the whole advertisement which has a melancholic, sad character, the scenes with positive emotions (smile) may gain special importance. However, the situation is different in men (weaker memory encoding). These differences can be partially explained by different preferences regarding the nature of the adverts. Women have a greater preference for adverts that are active but pleasurable to watch, whereas men prefer them to be active but less pleasurable [36]. However, taking the specific example of the effect of emotional scenes (positive, smile) on men's and women's receipt of this type of advertising, the results are not conclusive. This issue requires further examination.

On the other hand, differences in signal power changes in the alpha frequency range between the right and left frontal regions of the brain (frontal asymmetry) allow us to examine the degree of interest in the presented stimulus (the advertisement scenes). This is consistent with the assumptions of Davidson's approach/withdrawal model [21,112-114]. Higher values of frontal alpha asymmetry reflect greater left hemisphere activity. Note that alpha power is inversely related to cortical activity, and the decreased values of alpha band power indicate increased cortical activity (higher activity-disappearance of the alpha rhythm). What is more, using the logarithm when determining the difference in power makes it possible to provide a correction for the overall alpha power. This is of practical importance, if only because of individual structure (thickness) of the human skull, which in turn affects the signal amplitude $[72,75,115]$. Stimulating the respondents 
with visual and auditory material (advertisement) allowed us to determine approach and withdrawal patterns in reaction to the stimulus. The higher women's AW values regarding scenes S2 and S6 were attributed to the positive reception of these particular fragments. The protagonist's smile thus acted similarly to memory encoding. Significant differences in interest (represented by AW) between men and women were seen regarding S7. Relative to the other scenes, S7 visually did not appear to be attractive (Figure 5). The white background transitioning to black with information about the construction of an adult hospice produces a saddening effect. The introduction of an additional stimulus in this scene, namely the voiceover, was probably supposed to emphasize the purpose of this advertisement. This type of stimuli (sound effects) enhances the dynamic change of affective states, which is reflected in the brain processes [106]. The power of these changes and its impact on the viewer, including various emotional states, have been confirmed by numerous studies [116-118]. However, it is important to note that the audio impact is determined by the viewers' individual preferences correlated with their gender, age, personality or cognitive style [106]. The voiceover narration limited to S7 only was designed to capture the attention and evoke specific emotional states in the audience. The results of the present study suggest that such a combination of message elements as used in scene S7 (black background, white subtitle, voiceover replacing the background music of the advertisement) may be more effective in arousing interest in men, while in women the opposite is true.

The comparison of electroencephalographic measurements with behavioral data (questionnaire) on remembering revealed significant discrepancies. In the case of the analysed scenes, EEG measurements showed that, in women, memory encoding processes were activated to a greater extent than in men (for all scenes). The survey data, however, do not give a clear answer on the subject of remembering an advertisement. When asked whether they had seen an advertisement for a brand, product or service and mentioning various names (including hospice), men recalled the advertisement to a greater extent than women. In contrast, when asked about the details of the advertisement, slightly more women recalled some parts of it. For scenes S2 and S6, half of the women and men were able to recall some parts of it and, for S7, not-significantly more women were able to do so. That can be explained by the fact that not all physiological processes are under volitional control, i.e., enter the conscious sphere [119]. This has been confirmed by the fact that measurements of human physiological processes in specific research situations expand the range of observable parameters and human reactions. Thus, they give us additional information that cannot be obtained from humans by means of declarative methods. This can be explained by the functioning of their subconsciousness. When using declarative methods, it is important how the question is formulated. In the case of closed questions (with answers), it is easier to reconstruct what one has seen before. In open-ended questions (suggesting nothing, hinting) it is more difficult. When the ad was shown again (at the beginning), most respondents recalled its details. It is therefore difficult to draw clear conclusions from such survey research. This applies both to the study of the level of recall by the entire research group and the breakdown by gender. Perhaps an interview would be a more reliable means of declarative research. The non-declarative character of physiological measurements means that they are not based on conscious, expressed human responses to the questions posed to them. Therefore, they are treated as more objective and can be an important complement to declarative research. When studying the impact of advertising on viewers (studying the impact they experience when viewing it), measures based on physiological measurements appear more reliable $[24,25]$.

\section{Conclusions}

Various organizations operating within the health care system use the advertising message to achieve specific goals, usually corresponding with the profile of their operations. Hospices, being institutions functioning within this system, often make use of such forms of communication to raise funds for their activities. The use of cognitive neuroscience 
methods in this area can improve the effectiveness of such a message. The study of physiological (as well as neurophysiological) parameters of a human body that determine the response to the presented stimuli can significantly broaden the scope of information that can be obtained about the reception of a given message. It provides information that cannot be collected in a course of declarative research.

Nonetheless, studies have shown that physiological measurements (even those performed to a limited extent) provide valuable additional information and are an excellent complement to traditional testing methods. They make it possible to assess and predict behavioral involvement at the population level as regards the reception of an advertising message. Moreover, they help identify scenes (or even single frames), which are likely to affect audiences to a varying degree, i.e., depending on their sex, which is particularly interesting for this study. Due to sexual dimorphism of the human brain, this type of research should be designed accordingly. The results confirmed that different scenes can trigger different cognitive reactions in women and men. This is a valuable indication for designers of advertising messages. The study also showed that statements are not always consistent with neural measurements. The verbal message is the result of processing primary information produced in the brain. It can therefore be subject to intentional or unintentional error. In addition, there are situations in which people are unable to extract information from their memory at a given moment and convey it verbally. It concerns especially feelings, emotions connected with various external stimuli. Additionally, this is exactly what appears in the dynamically changing advertising message.

The knowledge the physiological measures provide may therefore be applied in the process of creating messages targeted at a specific audience and with the intention of shaping specific behavior. This confirms the wide applicability of cognitive neuroscience methods, also in the area of health promotion and health literacy. In this field, the above methods are considered innovative, and their potential opens up the perspective of their growing attractiveness and wider applicability. They also remain attractive in terms of boosting communication between organizations and their environment, and consequently improving the generally understood management processes regarding the issues that are of key importance to these organizations.

Author Contributions: Conceptualization, M.P., K.G.-L. and K.N.; methodology, M.P. and K.N.; software, M.P.; validation, M.P.; formal analysis, M.P., K.G.-L. and K.N.; investigation, M.P., K.G.-L. and K.N.; resources, M.P. and K.N.; data curation, M.P.; writing—original draft preparation, M.P., K.G.-L. and K.N.; writing—review and editing, M.P. and K.G.-L.; visualization, M.P.; supervision, M.P., K.G.-L. and K.N.; project administration, K.N.; funding acquisition, M.P. All authors have read and agreed to the published version of the manuscript.

Funding: The project is financed within the framework of the program of the Minister of Science and Higher Education under the name "Regional Excellence Initiative" in the years 2019-2022; project number 001/RID/2018/19; the amount of financing PLN 10,684,000.00.

Institutional Review Board Statement: The study was conducted according to the guidelines of the Declaration of Helsinki, and approved by the Bioethics Committees at Regional Chamber of Physicians in Szczecin (protocol code: 02/KB/VII/2020, date: 18.06.2020).

Informed Consent Statement: Informed consent was obtained from all subjects involved in the study.

Data Availability Statement: The data relative to the study could be obtained by sending an e-mail to mateusz.piwowarski@usz.edu.pl. Dr Piwowarski will return directly the files related to the data gathered by the study.

Conflicts of Interest: The authors declare no conflict of interest. The funders had no role in the design of the study; in the collection, analyses, or interpretation of data; in the writing of the manuscript, or in the decision to publish the results. 


\section{References}

1. Institute of Medicine Health. Literacy: A Prescription to End Confusion; Nielsen-Bohlman, L., Panzer, A.M., Kindig, D.A., Eds.; National Academies Press: Washington, DC, USA, 2004; ISBN 978-0-309-28332-8.

2. Quah, S.R.; Cockerham, W.C. International Encyclopedia of Public Health; Academic Press: Cambridge, MA, USA, 2017. ISBN 978-0-12-803708-9.

3. Nutbeam, D. Health Literacy as a Public Health Goal: A Challenge for Contemporary Health Education and Communication Strategies into the 21st Century. Health Promot. Int. 2000, 15, 259-267. [CrossRef]

4. Simonds, S.K. Health Education as Social Policy. Health Educ. Monogr. 1974, 2, 1-10. [CrossRef]

5. Nutbeam, D. Health Promotion Glossary. Health Promot. Int. 1998, 13, 349-364. [CrossRef]

6. Berkman, N.D.; Sheridan, S.L.; Donahue, K.E.; Halpern, D.J.; Crotty, K. Low Health Literacy and Health Outcomes: An Updated Systematic Review. Ann. Intern. Med. 2011, 155, 97-107. [CrossRef] [PubMed]

7. Willcox, J.C.; Ball, K.; Campbell, K.J.; Crawford, D.A.; Wilkinson, S.A. Correlates of Pregnant Women's Gestational Weight Gain Knowledge. Midwifery 2017, 49, 32-39. [CrossRef] [PubMed]

8. Garcia-Codina, O.; Juvinyà-Canal, D.; Amil-Bujan, P.; Bertran-Noguer, C.; González-Mestre, M.A.; Masachs-Fatjo, E.; Santaeugènia, S.J.; Magrinyà-Rull, P.; Saltó-Cerezuela, E. Determinants of Health Literacy in the General Population: Results of the Catalan Health Survey. BMC Public Health 2019, 19, 1122. [CrossRef]

9. Sørensen, K.; Van den Broucke, S.; Fullam, J.; Doyle, G.; Pelikan, J.; Slonska, Z.; Brand, H.; (HLS-EU) Consortium Health Literacy Project European. Health Literacy and Public Health: A Systematic Review and Integration of Definitions and Models. BMC Public Health 2012, 12, 80. [CrossRef]

10. Ishikawa, H.; Yano, E. Patient Health Literacy and Participation in the Health-Care Process. Health Expect 2008, 11, 113-122. [CrossRef]

11. Freedman, D.A.; Bess, K.D.; Tucker, H.A.; Boyd, D.L.; Tuchman, A.M.; Wallston, K.A. Public Health Literacy Defined. Am. J. Prev. Med. 2009, 36, 446-451. [CrossRef]

12. Kickbusch, I.S. Health Literacy: Addressing the Health and Education Divide. Health Promot. Int. 2001, 16, 289-297. [CrossRef]

13. Great Britain; Medicine and Healthcare products Regulatory Agency; Committee on Safety of Medicines Working Group on Patient Information. Always Read the Leaflet: Getting the Best Information with Every Medicine; Stationery Office: London, UK, 2005; ISBN 978-0-11-703556-0.

14. Zarcadoolas, C.; Pleasant, A.; Greer, D.S. Understanding Health Literacy: An Expanded Model. Health Promot. Int. 2005, 20, 195-203. [CrossRef]

15. Brach, C. The Journey to Become a Health Literate Organization: A Snapshot of Health System Improvement. Stud. Health Technol. Inform. 2017, 240, 203-237.

16. Vamos, C.A.; Thompson, E.L.; Griner, S.B.; Liggett, L.G.; Daley, E.M. Applying Organizational Health Literacy to Maternal and Child Health. Matern. Child. Health J. 2019, 23, 597-602. [CrossRef]

17. Raupp, J.; Hoffjann, O. Understanding Strategy in Communication Management. J. Commun. Manag. 2012, 16, 146-161. [CrossRef]

18. Luthra, D.; Singh, K. Organizational Communication and Management Effectiveness: An Analytical Study at Various Managerial Levels. Int. J. Manag. Bus. Stud. 2015, 5, 59-66.

19. Ratzan, S.C. Health Literacy: Communication for the Public Good. Health Promot. Int. 2001, 16, 207-214. [CrossRef]

20. Auverset, L.A.; Billings, A.C. Relationships between Social TV and Enjoyment: A Content Analysis of The Walking Dead's Story Sync Experience. Soc. Media+ Soc. 2016, 2, 205630511666217. [CrossRef]

21. Shestyuk, A.Y.; Kasinathan, K.; Karapoondinott, V.; Knight, R.T.; Gurumoorthy, R. Individual EEG measures of attention, memory, and motivation predict population level TV viewership and Twitter engagement. PLoS ONE 2019, 14, e0214507. [CrossRef]

22. Hunter, S.D., III; Chinta, R.; Smith, S.; Shamim, A.; Bawazir, A. Moneyball for TV: A Model for Forecasting the Audience of New Dramatic Television Series. Stud. Media Commun. 2016, 4, 13-22. [CrossRef]

23. Cha, J. Television Use in the 21st Century: An Exploration of Television and Social Television Use in a Multiplatform Environment. First Monday FM 2016, 21. [CrossRef]

24. Zajonc, R.B.; McIntosh, D.N. Emotions Research: Some Promising Questions and Some Questionable Promises. Psychol. Sci. 1992, 3, 70-74. [CrossRef]

25. Davidson, R.J. What Does the Prefrontal Cortex "Do" in Affect: Perspectives on Frontal EEG Asymmetry Research. Biol. Psychol. 2004, 67, 219-233. [CrossRef] [PubMed]

26. Libet, B. Mind Time: The Temporal Factor in Consciousness; Perspectives in Cognitive Neuroscience; Harvard University Press: Cambridge, MA, USA, 2005; ISBN 978-0-674-01846-4.

27. Huizenga, H.M.; Wetzels, R.; van Ravenzwaaij, D.; Wagenmakers, E.-J. Four Empirical Tests of Unconscious Thought Theory. Organ. Behav. Hum. Decis. Process. 2012, 117, 332-340. [CrossRef]

28. Perlovsky, L.; Schoeller, F. Unconscious Emotions of Human Learning. Phys. Life Rev. 2019, 31, 257-262. [CrossRef] [PubMed]

29. Winkielman, P. Bob Zajonc and the Unconscious Emotion. Emot. Rev. 2010, 2, 353-362. [CrossRef]

30. Ohme, R.; Reykowska, D.; Wiener, D.; Choromanska, A. Analysis of Neurophysiological Reactions to Advertising Stimuli by Means of EEG and Galvanic Skin Response Measures. J. Neurosci. Psychol. Econ. 2009, 2, 21-31. [CrossRef]

31. Smith, E.E.; Kosslyn, S.M. Cognitive Psychology: Mind and Brain; Pearson/Prentice Hall: Upper Saddle River, NJ, USA, 2007; ISBN 978-0-13-182508-6. 
32. Speck, O.; Ernst, T.; Braun, J.; Koch, C.; Miller, E.; Chang, L. Gender Differences in the Functional Organization of the Brain for Working Memory. NeuroReport 2000, 11, 2581-2585. [CrossRef]

33. Lee, T.M.C.; Liu, H.-L.; Chan, C.C.H.; Fang, S.-Y.; Gao, J.-H. Neural Activities Associated with Emotion Recognition Observed in Men and Women. Mol. Psychiatry 2005, 10, 450-455. [CrossRef]

34. Bell, E.C.; Willson, M.C.; Wilman, A.H.; Dave, S.; Silverstone, P.H. Males and Females Differ in Brain Activation during Cognitive Tasks. NeuroImage 2006, 30, 529-538. [CrossRef]

35. Cartocci, G.; Modica, E.; Rossi, D.; Inguscio, B.M.S.; Aricò, P.; Martinez Levy, A.C.; Mancini, M.; Cherubino, P.; Babiloni, F. Antismoking Campaigns' Perception and Gender Differences: A Comparison among EEG Indices. Comput. Intell. Neurosci. 2019, 2019, 1-9. [CrossRef]

36. Cartocci, G.; Cherubino, P.; Rossi, D.; Modica, E.; Maglione, A.G.; di Flumeri, G.; Babiloni, F. Gender and Age Related Effects While Watching TV Advertisements: An EEG Study. Comput. Intell. Neurosci. 2016, 2016, 1-10. [CrossRef] [PubMed]

37. Vecchiato, G.; Maglione, A.G.; Cherubino, P.; Wasikowska, B.; Wawrzyniak, A.; Latuszynska, A.; Latuszynska, M.; Nermend, K.; Graziani, I.; Leucci, M.R.; et al. Neurophysiological Tools to Investigate Consumer's Gender Differences during the Observation of TV Commercials. Comput. Math. Methods Med. 2014, 2014, e912981. [CrossRef]

38. Lo, S.-Y.; King, J.-T.; Lin, C.-T. How Does Gender Stereotype Affect the Memory of Advertisements? A Behavioral and Electroencephalography Study. Front. Psychol. 2020, 11. [CrossRef] [PubMed]

39. Uva, T.; de Freitas, C.L.; Paiva, T. Neuroscience Technologies in Marketing: A Study of Gender and TV Advertisements Using Electroencephalography. IJTMKT 2015, 10, 362. [CrossRef]

40. Lieberman, M.D. Social Cognitive Neuroscience: A Review of Core Processes. Annu. Rev. Psychol. 2007, 58, 259-289. [CrossRef]

41. Kriegeskorte, N.; Douglas, P.K. Cognitive Computational Neuroscience. Nat. Neurosci. 2018, 21, 1148-1160. [CrossRef]

42. Whittingstall, K.; Bartels, A.; Singh, V.; Kwon, S.; Logothetis, N.K. Integration of EEG Source Imaging and FMRI during Continuous Viewing of Natural Movies. Magn. Reson. Imaging 2010, 28, 1135-1142. [CrossRef]

43. Vecchiato, G.; Astolfi, L.; De Vico Fallani, F.; Toppi, J.; Aloise, F.; Bez, F.; Wei, D.; Kong, W.; Dai, J.; Cincotti, F.; et al. On the Use of EEG or MEG Brain Imaging Tools in Neuromarketing Research. Comput. Intell. Neurosci. 2011, 2011, 643489. [CrossRef]

44. Ohme, R.; Reykowska, D.; Wiener, D.; Choromanska, A. Application of Frontal EEG Asymmetry to Advertising Research. J. Econ. Psychol. 2010, 31, 785-793. [CrossRef]

45. Mandelkow, H.; de Zwart, J.A.; Duyn, J.H. Linear Discriminant Analysis Achieves High Classification Accuracy for the BOLD FMRI Response to Naturalistic Movie Stimuli. Front. Hum. Neurosci. 2016, 10, 128. [CrossRef] [PubMed]

46. Kong, W.; Zhao, X.; Hu, S.; Vecchiato, G.; Babiloni, F. Electronic Evaluation for Video Commercials by Impression Index. Cogn. Neurodyn. 2013, 7, 531-535. [CrossRef] [PubMed]

47. Gordon, R.; Ciorciari, J.; van Laer, T. Using EEG to Examine the Role of Attention, Working Memory, Emotion, and Imagination in Narrative Transportation. Eur. J. Mark. 2018, 52, 92-117. [CrossRef]

48. Deitz, G.D.; Royne, M.B.; Peasley, M.C.; Huang, J. “Coco” EEG-Based Measures versus Panel Ratings: Predicting Social-Media Based Behavioral Responses to Super Bowl Ads. J. Adv. Res. 2016, 56, 217. [CrossRef]

49. Christoforou, C.; Papadopoulos, T.C.; Constantinidou, F.; Theodorou, M. Your Brain on the Movies: A Computational Approach for Predicting Box-Office Performance from Viewer's Brain Responses to Movie Trailers. Front. Neuroinform. 2017, 11, 72. [CrossRef] [PubMed]

50. Boksem, M.A.S.; Smidts, A. Brain Responses to Movie Trailers Predict Individual Preferences for Movies and Their PopulationWide Commercial Success. J. Mark. Res. 2015, 52, 482-492. [CrossRef]

51. Barnett, S.B.; Cerf, M. A Ticket for Your Thoughts: Method for Predicting Movie Trailer Recall and Future Ticket Sales Using Neural Similarity among Moviegoers. J. Consum. Res. 2017, ucw083. [CrossRef]

52. Vecchiato, G.; Toppi, J.; Astolfi, L.; De Vico Fallani, F.; Cincotti, F.; Mattia, D.; Bez, F.; Babiloni, F. Spectral EEG Frontal Asymmetries Correlate with the Experienced Pleasantness of TV Commercial Advertisements. Med. Biol. Eng. Comput. 2011, 49, 579-583. [CrossRef]

53. Vecchiato, G.; Cherubino, P.; Trettel, A.; Babiloni, F. Neuroelectrical Brain Imaging Tools for the Study of the Efficacy of TV Advertising Stimuli and Their Application to Neuromarketing; Springer: Berlin, Heidelberg, Germany, 2013; ISBN 978-3-642-38063-1.

54. Vecchiato, G.; Astolfi, L.; De Vico Fallani, F.; Cincotti, F.; Mattia, D.; Salinari, S.; Soranzo, R.; Babiloni, F. Changes in Brain Activity During the Observation of TV Commercials by Using EEG, GSR and HR Measurements. Brain. Topogr. 2010, 23, 165-179. [CrossRef]

55. Rothschild, M.L.; Thorson, E.; Reeves, B.; Hirsch, J.E.; Goldstein, R. EEG Activity and the Processing of Television Commercials. Commun. Res. 1986, 13, 182-220. [CrossRef]

56. Piwowarski, M. Neuromarketing Tools in Studies on Models of Social Issue Advertising Impact on Recipients. In Problems, Methods and Tools in Experimental and Behavioral Economics; Nermend, K., Łatuszyńska, M., Eds.; Springer International Publishing: Cham, Switzerland, 2018; pp. 99-111; ISBN 978-3-319-99186-3.

57. Piwowarski, M. EEG in Analysis of the Level of Interest in Social Issue Advertising. Procedia Comput. Sci. 2018, 126, 1945-1953. [CrossRef]

58. Piwowarski, M.; Nermend, K. Cognitive Neuroscience in the Design Process of Social Advertising. Procedia Comput. Sci. 2020, 176, 2959-2968. [CrossRef] 
59. Borawska, A.; Oleksy, T.; Maison, D. Do Negative Emotions in Social Advertising Really Work? Confrontation of Classic vs. EEG Reaction toward Advertising That Promotes Safe Driving. PLoS ONE 2020, 15, e0233036. [CrossRef]

60. Alsakaa, A.A.; Borawska, A.; Borawski, M.; Łatuszyńska, M.; Piwowarski, M.; Babiloni\|, F.; Nermend, K. Cognitive Neuroscience Techniques in Determining the Right Time of Advertising. IOP Conf. Ser. Mater. Sci. Eng. 2020, 671, 012033. [CrossRef]

61. Fortunato, V.C.R.; Giraldi, J.D.M.E.; De Oliveira, J.H.C. A Review of Studies on Neuromarketing: Practical Results, Techniques, Contributions and Limitations. JMR 2014, 6, 201. [CrossRef]

62. Feldman, J.M.; Lynch, J.G. Self-Generated Validity and Other Effects of Measurement on Belief, Attitude, Intention, and Behavior. J. Appl. Psychol. 1988, 73, 421-435. [CrossRef]

63. Falk, E.B.; Berkman, E.T.; Mann, T.; Harrison, B.; Lieberman, M.D. Predicting Persuasion-Induced Behavior Change from the Brain. J. Neurosci. 2010, 30, 8421-8424. [CrossRef]

64. Sánchez-Fernández, J.; Casado-Aranda, L.-A.; Bastidas-Manzano, A.-B. Consumer Neuroscience Techniques in Advertising Research: A Bibliometric Citation Analysis. Sustainability 2021, 13, 1589. [CrossRef]

65. Schafer, E.W.P. Brain Responses While Viewing Television Reflect Program Interest. Int. J. Neurosci. 1978, 8, 71-77. [CrossRef]

66. Venkatraman, V.; Dimoka, A.; Pavlou, P.A.; Vo, K.; Hampton, W.; Bollinger, B.; Hershfield, H.E.; Ishihara, M.; Winer, R.S. Predicting Advertising Success beyond Traditional Measures: New Insights from Neurophysiological Methods and Market Response Modeling. J. Mark. Res. 2015, 52, 436-452. [CrossRef]

67. Harmon-Jones, E.; Allen, J.J.B. Behavioral Activation Sensitivity and Resting Frontal EEG Asymmetry: Covariation of Putative Indicators Related to Risk for Mood Disorders. J. Abnorm. Psychol. 1997, 106, 159-163. [CrossRef]

68. Gevins, A.; Smith, M.E.; McEvoy, L.K.; Leong, H.; Le, J. Electroencephalographic Imaging of Higher Brain Function. Phil. Trans. R. Soc. Lond. B 1999, 354, 1125-1134. [CrossRef]

69. Harris, J.M.; Ciorciari, J.; Gountas, J. Consumer Neuroscience and Digital/Social Media Health/Social Cause Advertisement Effectiveness. Behav. Sci. 2019, 9, 42. [CrossRef]

70. Zhao, G.; Zhang, Y.; Ge, Y. Frontal EEG Asymmetry and Middle Line Power Difference in Discrete Emotions. Front. Behav. Neurosci. 2018, 12, 225. [CrossRef]

71. Hagemann, D.; Naumann, E.; Becker, G.; Maier, S.; Bartussek, D. Frontal Brain Asymmetry and Affective Style: A Conceptual Replication. Psychophysiology 1998, 35, 372-388. [CrossRef]

72. Allen, J.J.B.; Coan, J.A.; Nazarian, M. Issues and Assumptions on the Road from Raw Signals to Metrics of Frontal EEG Asymmetry in Emotion. Biol. Psychol. 2004, 67, 183-218. [CrossRef] [PubMed]

73. Davidson, R.J.; Ekman, P.; Saron, C.D.; Senulis, J.A.; Friesen, W.V. Approach-Withdrawal and Cerebral Asymmetry: Emotional Expression and Brain Physiology. I. J. Pers. Soc. Psychol. 1990, 58, 330-341. [CrossRef] [PubMed]

74. Di Flumeri, G.; Herrero, M.T.; Trettel, A.; Cherubino, P.; Maglione, A.G.; Colosimo, A.; Moneta, E.; Peparaio, M.; Babiloni, F. EEG Frontal Asymmetry Related to Pleasantness of Olfactory Stimuli in Young Subjects. In Selected Issues in Experimental Economics; Nermend, K., Łatuszyńska, M., Eds.; Springer Proceedings in Business and Economics; Springer International Publishing: Cham, Switzerland, 2016; pp. 373-381; ISBN 978-3-319-28417-0.

75. Smith, E.E.; Reznik, S.J.; Stewart, J.L.; Allen, J.J.B. Assessing and Conceptualizing Frontal EEG Asymmetry: An Updated Primer on Recording, Processing, Analyzing, and Interpreting Frontal Alpha Asymmetry. Int. J. Psychophysiol. 2017, 111, 98-114. [CrossRef] [PubMed]

76. Pizzagalli, D.A.; Sherwood, R.J.; Henriques, J.B.; Davidson, R.J. Frontal Brain Asymmetry and Reward Responsiveness: A Source-Localization Study. Psychol. Sci. 2005, 16, 805-813. [CrossRef]

77. Berridge, C.W.; Espana, R.A.; Stalnaker, T.A. Stress and Coping: Asymmetry of Dopamine Efferents within Prefrontal Cortex; Hugdahl, K., Davidson, R.J., Eds.; The Asymmetrical Brain; MIT Press: Cambridge, MA, USA, 2003; pp. 69-103.

78. Hewig, J.; Hagemann, D.; Seifert, J.; Naumann, E.; Bartussek, D. The Relation of Cortical Activity and BIS/BAS on the Trait Level. Biol. Psychol. 2006, 71, 42-53. [CrossRef]

79. Vecchiato, G.; Kong, W.; Maglione, A.G.; Wei, D. Understanding the Impact of TV Commercials: Electrical Neuroimaging. IEEE Pulse 2012, 3, 42-47. [CrossRef]

80. Summerfield, C.; Mangels, J.A. Coherent Theta-Band EEG Activity Predicts Item-Context Binding during Encoding. NeuroImage 2005, 24, 692-703. [CrossRef]

81. Werkle-Bergner, M.; Müller, V.; Li, S.-C.; Lindenberger, U. Cortical EEG Correlates of Successful Memory Encoding: Implications for Lifespan Comparisons. Neurosci. Biobehav. Rev. 2006, 30, 839-854. [CrossRef] [PubMed]

82. 8Blanchet, S. New Questions on the Hemispheric Encoding/Retrieval Asymmetry (HERA) Model Assessed by Divided VisualField Tachistoscopy in Normal Subjects. Neuropsychologia 2001, 39, 502-509. [CrossRef]

83. Habib, R.; Nyberg, L.; Tulving, E. Hemispheric Asymmetries of Memory: The HERA Model Revisited. Trends Cogn. Sci. 2003, 7, 241-245. [CrossRef]

84. Tulving, E.; Kapur, S.; Markowitsch, H.J.; Craik, F.I.; Habib, R.; Houle, S. Neuroanatomical Correlates of Retrieval in Episodic Memory: Auditory Sentence Recognition. Proc. Natl. Acad. Sci. USA 1994, 91, 2012-2015. [CrossRef] [PubMed]

85. Osipova, D.; Takashima, A.; Oostenveld, R.; Fernández, G.; Maris, E.; Jensen, O. Theta and Gamma Oscillations Predict Encoding and Retrieval of Declarative Memory. J. Neurosci. 2006, 26, 7523-7531. [CrossRef] [PubMed]

86. Klimesch, W. EEG Alpha and Theta Oscillations Reflect Cognitive and Memory Performance: A Review and Analysis. Brain Res. Rev. 1999, 29, 169-195. [CrossRef] 
87. Benchenane, K.; Tiesinga, P.H.; Battaglia, F.P. Oscillations in the Prefrontal Cortex: A Gateway to Memory and Attention. Curr. Opin. Neurobiol. 2011, 21, 475-485. [CrossRef] [PubMed]

88. Alekseichuk, I.; Turi, Z.; Amador de Lara, G.; Antal, A.; Paulus, W. Spatial Working Memory in Humans Depends on Theta and High Gamma Synchronization in the Prefrontal Cortex. Curr. Biol. 2016, 26, 1513-1521. [CrossRef]

89. Astolfi, L.; Soranzo, R.; Cincotti, F.; Mattia, D.; Scarano, G.; Gaudiano, I.; Marciani, M.G.; Salinari, S.; De Vico Fallani, F.; Babiloni, F. Assessing the Memorization of TV Commercials with the Use of High Resolution EEG: A Pilot Study. In Proceedings of the 2008 30th Annual International Conference of the IEEE Engineering in Medicine and Biology Society, Vancouver, BC, Canada, 20-24 August 2008; pp. 3755-3758.

90. Wang, J.; Xu, W. Research of Video Advertisements Effect Based on EEG: ERSP and Emotion for Commercial Effect. In Proceedings of the 2016 13th International Conference on Service Systems and Service Management (ICSSSM), Kunming, China, 24-26 June 2016; Volume 24-26, pp. 1-5.

91. Astolfi, L.; De Vico Fallani, F.; Cincotti, F.; Mattia, D.; Bianchi, L.; Marciani, M.G.; Salinari, S.; Colosimo, A.; Tocci, A.; Soranzo, R.; et al. Neural Basis for Brain Responses to TV Commercials: A High-Resolution EEG Study. IEEE Trans. Neural Syst. Rehabil. Eng. 2008, 16, 522-531. [CrossRef]

92. Vecchiato, G.; Babiloni, F. Neurophysiological Measurements of Memorization and Pleasantness in Neuromarketing Experiments. In Analysis of Verbal and Nonverbal Communication and Enactment. The Processing Issues; Esposito, A., Vinciarelli, A., Vicsi, K., Pelachaud, C., Nijholt, A., Eds.; Lecture Notes in Computer Science; Springer: Berlin/Heidelberg, Germany, 2011; Volume 6800, pp. 294-308. ISBN 978-3-642-25774-2.

93. Rossiter, J.R.; Silberstein, R.B.; Harris, P.G.; Nield, G. Brain-Imaging Detection of Visual Scene Encoding in Long-Term Memory for TV Commercials. JAR 2001, 41, 13-21. [CrossRef]

94. Piwowarski, M. Cognitive Neuroscience Techniques in Examining the Effectiveness of Social Advertisements. In Neuroeconomic and Behavioral Aspects of Decision Making; Nermend, K., Łatuszyńska, M., Eds.; Springer International Publishing: Cham, Switzerland, 2017; pp. 341-352. ISBN 978-3-319-62937-7.

95. Nermend, K.; Piwowarski, M. Cognitive Neuroscience Techniques in Supporting Decision Making and the Analysis of Social Campaign. IJSSES 2018, 5. [CrossRef]

96. Piwowarski, M.; Singh, U.S.; Nermend, K. Application of EEG Metrics in the Decision-Making Process. In Experimental and Quantitative Methods in Contemporary Economics; Nermend, K., Łatuszyńska, M., Eds.; Springer Proceedings in Business and Economics; Springer International Publishing: Cham, Switzerland, 2020; pp. 187-199; ISBN 978-3-030-30250-4.

97. Borawska, A.; Piwowarski, M.; Borawski, M. Techniques of Cognitive Neuroscience in the Assessment and Measurement of Environmental Public Service Announcements Effectiveness; Callaos, N., Peoples, B., Sánchez, B., Savoie, M., Eds.; Winter Garden: Orlando, FL, USA; International Institue of Informatics of Systemics: Orlando, FL, USA, 2019; Volume 1, pp. 110-115. ISBN 978-1-950492-07-7.

98. Ciorciari, J.; Pfeifer, J.; Gountas, J. An EEG Study on Emotional Intelligence and Advertising Message Effectiveness. Behav. Sci. 2019, 9, 88. [CrossRef] [PubMed]

99. World Medical Association. World Medical Association Declaration of Helsinki: Ethical Principles for Medical Research Involving Human Subjects. JAMA 2013, 310, 2191. [CrossRef] [PubMed]

100. Lang, P.J.; Bradley, M.M.; Cuthbert, B.N. International Affective Picture System (IAPS): Technical Manual and Affective Ratings. NIMH Center for the Study of Emotion and Attention, University of Florida: Gainesville, FL, USA, 1997 ; pp. 39-58.

101. Delorme, A.; Makeig, S. EEGLAB: An Open Source Toolbox for Analysis of Single-Trial EEG Dynamics Including Independent Component Analysis. J. Neurosci. Methods 2004, 134, 9-21. [CrossRef] [PubMed]

102. Bell, A.J.; Sejnowski, T.J. An Information-Maximization Approach to Blind Separation and Blind Deconvolution. Neural Comput. 1995, 7, 1129-1159. [CrossRef] [PubMed]

103. Corcoran, A.W.; Alday, P.M.; Schlesewsky, M.; Bornkessel-Schlesewsky, I. Toward a Reliable, Automated Method of Individual Alpha Frequency (IAF) Quantification. Psychophysiology 2018, 55, e13064. [CrossRef]

104. Lehmann, D.; Michel, C.M. Intracerebral Dipole Source Localization for FFT Power Maps. Electroencephalogr. Clin. Neurophysiol. 1990, 76, 271-276. [CrossRef]

105. Lehmann, D.; Skrandies, W. Reference-Free Identification of Components of Checkerboard-Evoked Multichannel Potential Fields. Electroencephalogr. Clin. Neurophysiol. 1980, 48, 609-621. [CrossRef]

106. Quarto, T.; Blasi, G.; Pallesen, K.J.; Bertolino, A.; Brattico, E. Implicit Processing of Visual Emotions Is Affected by Sound-Induced Affective States and Individual Affective Traits. PLoS ONE 2014, 9, e103278. [CrossRef]

107. Smith, M.E.; Gevins, A. Attention and Brain Activity While Watching Television: Components of Viewer Engagement. Media Psychol. 2004, 6, 285-305. [CrossRef]

108. Kensinger, E.A. Remembering the Details: Effects of Emotion. Emot. Rev. 2009, 1, 99-113. [CrossRef] [PubMed]

109. Yonelinas, A.P.; Ritchey, M. The Slow Forgetting of Emotional Episodic Memories: An Emotional Binding Account. Trends Cogn. Sci. 2015, 19, 259-267. [CrossRef]

110. Mather, M.; Sutherland, M.R. Arousal-Biased Competition in Perception and Memory. Perspect. Psychol. Sci. $2011,6,114-133$. [CrossRef] [PubMed]

111. Bowen, H.J.; Kensinger, E.A. Recapitulation of Emotional Source Context during Memory Retrieval. Cortex 2017, 91, 142-156. [CrossRef] [PubMed] 
112. Davidson, R.J. Cerebral Asymmetry and Emotion: Conceptual and Methodological Conundrums. Cogn. Emot. 1993, 7, 115-138. [CrossRef]

113. Davidson, R.J. Affective Style and Affective Disorders: Perspectives from Affective Neuroscience. Cogn. Emot. 1998, 12, 307-330. [CrossRef]

114. Coan, J.A.; Allen, J.J.B. Frontal EEG Asymmetry as a Moderator and Mediator of Emotion. Biol. Psychol. 2004, 67, 7-50. [CrossRef]

115. Eshel, Y.; Witman, S.; Rosenfeld, M.; Abboud, S. Correlation between Skull Thickness Asymmetry and Scalp Potential Estimated by a Numerical Model of the Head. IEEE Trans. Biomed. Eng. 1995, 42, 242-249. [CrossRef]

116. Lesiuk, T. The Effect of Preferred Music on Mood and Performance in a High-Cognitive Demand Occupation. J. Music Ther. 2010, 47, 137-154. [CrossRef]

117. Chanda, M.L.; Levitin, D.J. The Neurochemistry of Music. Trends Cogn. Sci. 2013, 17, 179-193. [CrossRef] [PubMed]

118. Liebenthal, E.; Silbersweig, D.A.; Stern, E. The Language, Tone and Prosody of Emotions: Neural Substrates and Dynamics of Spoken-Word Emotion Perception. Front. Neurosci. 2016, 10. [CrossRef] [PubMed]

119. Bargh, J.; Chartrand, T. The Unbearable Automaticity of Being. Am. Psychol. 1999, 54, 462-479. [CrossRef] 